Chapter Title: WALL PAINTINGS IN THE CHÂTEAU DE GERMOLLES: AN INTERDISCIPLINARY PROJECT FOR THE REDISCOVERY OF A UNIQUE FOURTEENTHCENTURY DECORATION Chapter Author(s): CHRISTIAN DEGRIGNY and FRANCESCA PIQUÉ

Book Title: Digital Techniques for Documenting and Preserving Cultural Heritage Book Editor(s): ANNA BENTKOWSKA-KAFEL, LINDSAY MacDONALD

Published by: Arc Humanities Press. (2017)

Stable URL: https://www.jstor.org/stable/j.ctt1xp3w16.11

JSTOR is a not-for-profit service that helps scholars, researchers, and students discover, use, and build upon a wide range of content in a trusted digital archive. We use information technology and tools to increase productivity and facilitate new forms of scholarship. For more information about JSTOR, please contact support@jstor.org.

Your use of the JSTOR archive indicates your acceptance of the Terms \& Conditions of Use, available at https://about.jstor.org/terms

This book is licensed under a Creative Commons Attribution-NonCommercialNoDerivatives 4.0 International License (CC BY-NC-ND 4.0). To view a copy of this license, visit https://creativecommons.org/licenses/by-nc-nd/4.0/. 
Chapter 4

\title{
WALL PAINTINGS IN THE CHÂTEAU DE GERMOLLES: AN INTERDISCIPLINARY PROJECT FOR THE REDISCOVERY OF A UNIQUE FOURTEENTH-CENTURY DECORATION
}

\author{
CHRISTIAN DEGRIGNY and FRANCESCA PIQUÉ \\ With contributions from MARCO CUCCHI,VINCENT DETALLE, \\ JEAN-PHILIPPE FARRUGIA, GAËTAN LE GOÏC, ALAMIN MANSOURI, \\ DOMINIQUE MARTOS-LEVIF, FRÉDÉRIC MÉRIENNE, AURÉLIE MOUNIER, \\ ANTHONY PAMART, CRISTINA TEDESCHI, JEAN-MARC VALLET, and STEFANIE WEFERS
}

\begin{abstract}
The aim of this study was to examine and document the wall paintings in the Château de Germolles. Situated in Burgundy, France, Germolles is the best preserved residence of the Dukes of Burgundy and was listed as a monument of national importance in 1989.

The medieval wall decoration of the Château de Germolles was rediscovered under the nineteenth-century plasters during World War II. Medieval accounts of the château provide a detailed list of the materials acquired to make the mural decoration, but this list is incongruous when compared with the current appearance of the paintings. The discrepancy between the archival and material evidence, and also the need to understand the complexity of the painting technique used were the main motivations for undertaking the case study described in this chapter. Imaging alongside more traditional examination techniques were utilized to record and document the mural decoration. The objectives of the case study were to distinguish the original materials from those applied during restoration, identify those materials, and correlate them with the archives. We also tried to understand the medieval painting techniques used and assess the condition of the paintings and stabilization requirements. Finally we aimed to find a sustainable solution for the management of the various types of data collected. Various techniques and investigations offered valuable insights into the materials and the painting technique used. To improve visitor experience, based on the information gained in the course of this study, a 3D virtual representation of the original decoration is currently proposed for display to the public visiting the Château de Germolles.
\end{abstract}

Keywords: Château de Germolles, dukes of Burgundy, Middle Ages, wall paintings, tin leaf decoration, spatial and spectral imaging techniques, $\mathrm{COSCH}$ 


\section{Introduction}

The Château de Germolles dates from the fourteenth century and is the best preserved residence of the Dukes of Burgundy. The wall paintings decorating the ducal piano nobile are a unique manifestation of the courtly love that permeated the courts of French and Italian dukes and princes of the time. Concealed sometime in the nineteenth century, the wall paintings were accidentally rediscovered during World War II. They were non-professionally uncovered in the 1970s and restored in 1989-95. No technical documentation accompanied these interventions. Some important questions, such as the level of authenticity of the mural decoration and the characteristics of the original medieval painting technique(s) remained unanswered. In this project, some of the most innovative imaging and analytical techniques were combined to address some of these questions. The project provided not only significant information on the material and techniques used in medieval times, but also a thorough assessment of the condition of the paintings. The data collected are vast and varied. They required proper management, including the storage of large raw files with metadata and the alignment between data. Our investigations enabled us to hypothesize how the exposed medieval paintings might have been created and how they might have looked originally. Augmented Reality renderings were created and are now used to disseminate both the insights gained and the cultural significance of the paintings to the public visiting the château.

\section{Earlier Research}

Situated in Southern Burgundy, 10 km west of Chalon-sur-Saône, the Château de Germolles is one of the few late fourteenth-century ducal residences surviving in France. It was owned by Margaret of Flanders (1350-1405), wife of Philip the Bold (1342-1404), Duke of Burgundy (reg. 1363-1404) and brother of Charles V, King of France. Built between 1380 and 1400, Germolles evidences the rural interests of French dukes.

When the Burgundian branch of the House of Valois ended in 1477, the château became property of the successive French kings who passed Germolles onto close vassals. As illustrated in figure 4.1 the original enclosed château suffered damage at various points in time: the roof of the southwest corner was lost sometime in the eighteenth century and the corresponding walls were demolished after the French Revolution. In 1873 a section of the east wing was destroyed by fire, definitively separating the main building from the rest of the château. The present owners acquired the château after this disaster. The entrance gate was listed as national cultural heritage in the mid-twentieth century, while the rest of the build- 


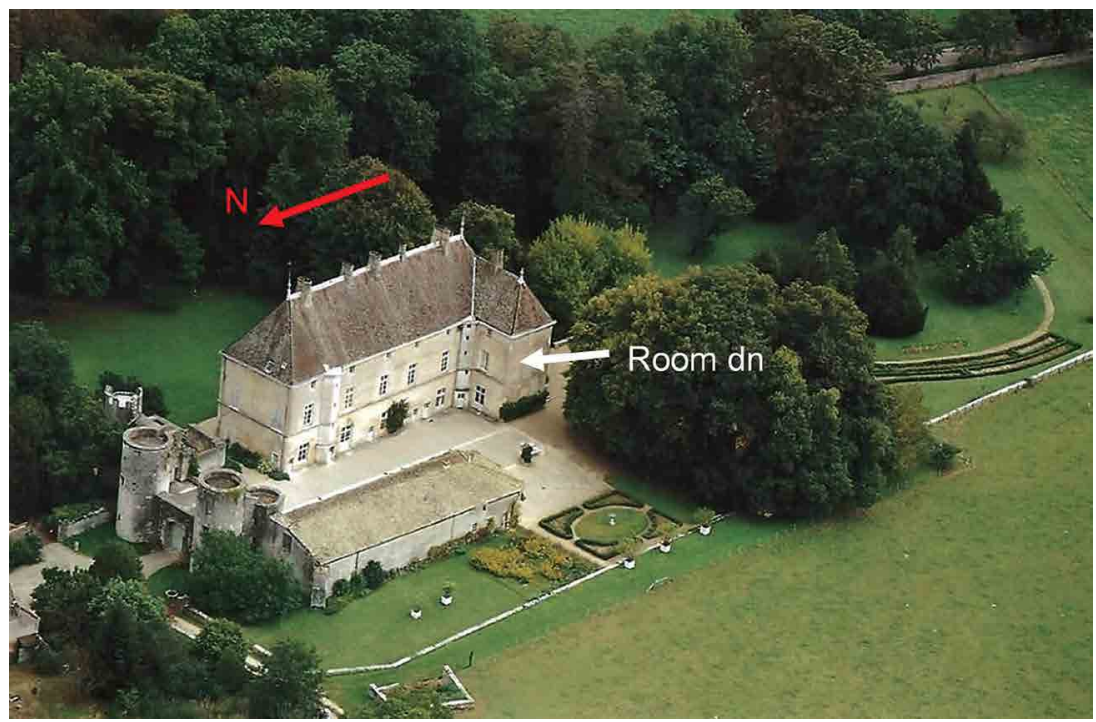

Figure 4.1. Aerial view of the Germolles estate from the northwest. The white arrow indicates the location of the room studied (dn) on the main building. The entrance gate is visible in the bottom left. The château was originally fully enclosed. Photo: Alain Rodrigue, 2007.

ing was listed in 1989 after the discovery of unique wall paintings dating back to the Dukes' period (Beck 2002). The château has been open to the public since the last fifty years and welcomes around 10,000 visitors per year.

Historic records held at the Archives départementales de Côte-d'Or (ADCO B4434-1) provide substantial information on the making of these paintings and their artists. The first (ducal) floor of the main building was decorated by one of the finest artist of the Burgundian School, Jean de Beaumetz and his workshop. Each of the adjacent apartments comprised a large bedroom and a corresponding dressing room. In modern times these apartments were divided, except the dressing room of Countess of Nevers, daughter-in-law of the Dukes. Her room, marked "dn" in figure 4.1 has survived in its original shape. In addition, all the rooms were redecorated with stucco plaster and wallpaper at the beginning of the nineteenth century. This new decoration was applied over the original wall paintings, which were keyed to improve adhesion of the stucco decoration. Some of this nineteenth-century decoration was removed in the 1970s after the rediscovery of the paintings in 1940. The paintings in the dressing rooms were restored between 1989 and 1995.

When entering the ducal floor, the visitor encounters on the walls a regular pattern of flowers - thistles, marguerites, roses-on a green background. In some 

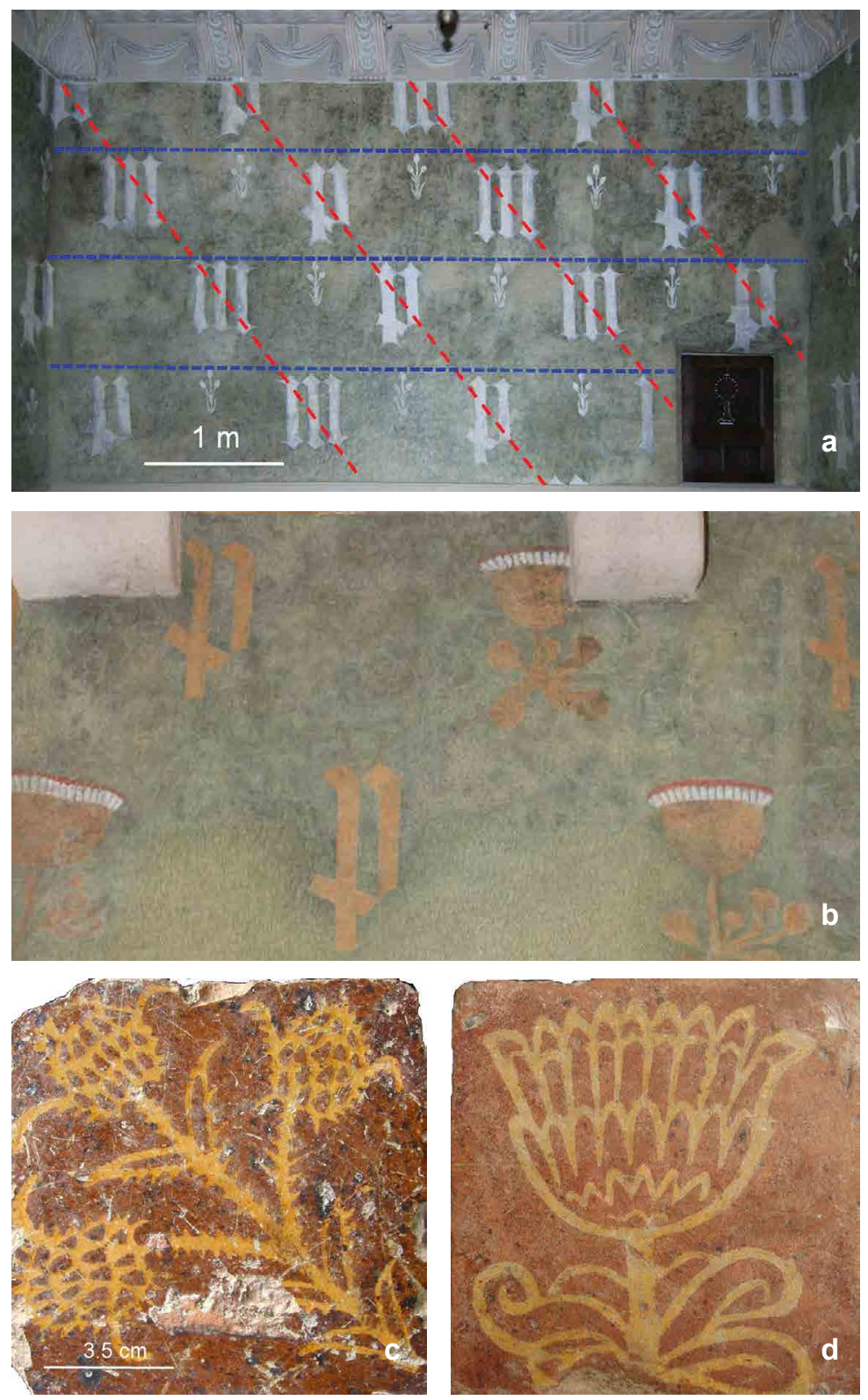

Figure 4.2. Details of wall paintings after conservation 1989-95

(a) in the dressing room of the Countess of Nevers; the red and blue dashed lines show the repetitiveness of geometrical pattern; (b) in the dressing room of Margaret of Flanders; (c) and (d) floor tiles reproduce the floral decoration of the walls. Photos (a) and (b) Francesca Piqué, 2013; (c) and (d) Château de Germolles, 2008. 
rooms they alternate with large initials of the first names of the Duke and/or the Duchess (fig. 4.2).

The decoration of the dressing room of Countess of Nevers consists of series of letters $\mathrm{P}$, letters $\mathrm{M}$, and thistles, alternating horizontally (shown by blue dashed lines in fig. 4.2a) and aligned diagonally (red dashed lines in fig. 4.2a). Figure 4.2b shows similar horizontal and diagonal patterns with letters $\mathrm{P}$ and marguerites, or daisies, in the dressing room of Margaret of Flanders. The decoration of the rooms included floor tiles matching the flowers depicted on the walls (fig. 4.2c-d). All the flowers are symbolic. Thistles speak of fidelity or protection, while marguerites in blossom refer to the Duchess's name and young age. These motifs were characteristic of the courtly love that was fashionable in the late fourteenth century.

The medieval accounts (ADCO B4434-1) of the château record the materials acquired to make the mural decoration and a detailed list of these materials provides useful information for the study of the paintings. However, the composition of the extant paintings and the materials identified do not match this information accurately. In particular, the records account for a large quantity of metal leaves, which are not visible in the paintings. They were probably lost in the course of

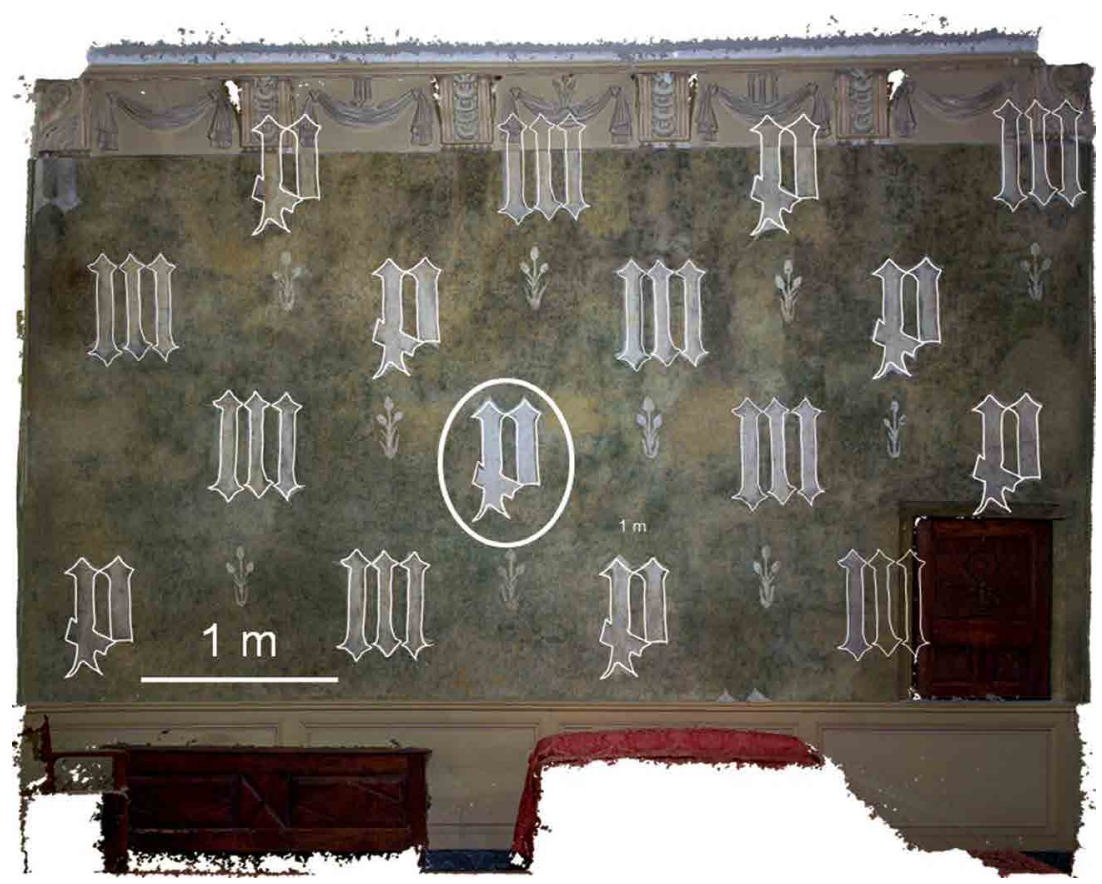

Figure 4.3. Orthophotograph of the west wall of room $d n$. The profiles of letters $P$ and $M$ are marked in white. The details of the letter $P$ circled in white are shown in figures 4.4 and 4.5. Photos: Julien Guery, 2014; the outlines Château de Germolles, 2016. 
centuries and through the uncovering operations. There is no mention in the accounts of a green pigment, which is extensively used in the background. This intriguing mismatch between the archival and material evidence, as well as the question of authenticity of the paintings, were the reasons for setting up our Germolles case study, conducted as an activity of the network, Colour and Space in Cultural Heritage (COSCH). Imaging and other non-invasive techniques, alongside more traditional examination techniques, were used to record and further document the mural decoration. All the exposed wall paintings were examined, but this chapter focuses on the comparative observations and analyses conducted in the dressing room of the Countess of Nevers, that is, room dn (Degrigny et al. 2016).

\section{Description of Work}

\section{Preliminary Documentation}

Basemaps of the walls were first created to document all future work. A photogrammetry campaign, using a Canon EOS 6D digital camera equipped with a $16 \mathrm{~mm}$ zoom lens, provided the orthophotographs. These digital images were used to manually trace the outlines of the letters. Figure 4.3 shows that on the west wall all $\mathrm{M}$ and $\mathrm{P}$ letters respectively seem to have the same form.

The extent of conservation work carried out in the twentieth century was revealed by infrared (IR) pictures (approx. 830-1000 nm) of the details of the walls, produced with a modified Canon EOS 5D Mark II digital camera which was equipped with filters and illuminated with a halogen Lowel V (500 W) light (Piqué 2013). Owing to the difference in IR absorption between the original and the repainted green background, the infrared pictures show clearly both the original and non-original areas. The losses caused by the nineteenth-century keying process were filled after the concealing stucco plaster had been removed. The missing decoration was recreated over these fills by repainting with material of
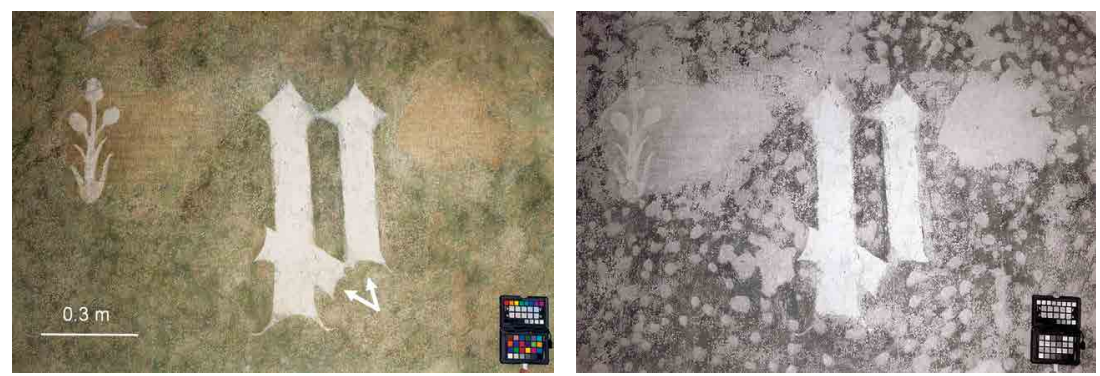

Figure 4.4. VIS and IR (approx. 830-1000 $\mathrm{nm}$ ) photographic images of the letter $P$ highlighted in figure 4.3. Arabesques in the lower part of the letter $P$ are indicated in the VIS image. They seem to disappear in the IR image. Photos: Francesca Piqué, 2016. 

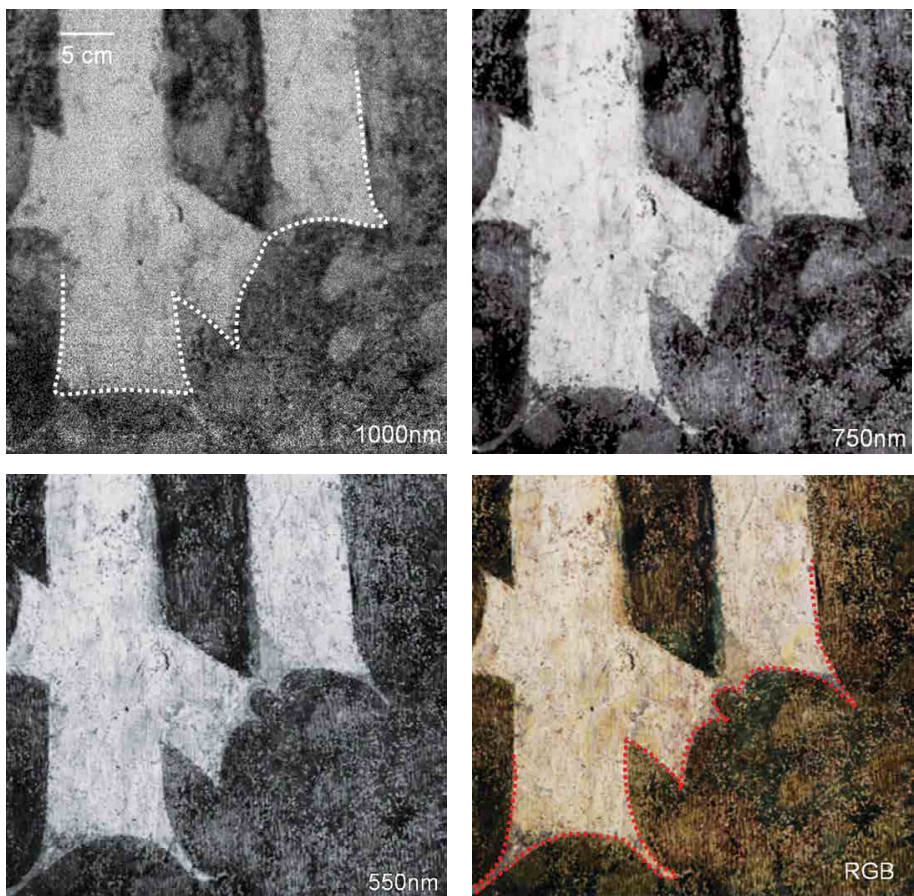

Figure 4.5. Hyperspectral imaging of the lower part of letter $P$, shown in figure 4.4. The white dotted line in the image at $1000 \mathrm{~nm}$ shows the original profile of the letter while the red dotted line in the RGB picture shows the profile of the embellished letter. Photos: Aurélie Mounier, 2016.

high IR reflection, while the authentic copper-based green which remained in the original portions of the plaster, had low IR reflection (high absorption) (fig. 4.4).

Furthermore, the embellishments (such as the arabesques) at the lower extremities of the P, in figure 4.4, are less visible in the IR image. Hyperspectral imaging was used to investigate these embellishments further. The CCD camera (HS-XX-V10E), developed by SPECIM, has a $1600 \times 840$ pixel resolution, a spectral resolution of $2.8 \mathrm{~nm}$ and a wavelength range between 400 to $1000 \mathrm{~nm}$. The wall paintings were illuminated by two halogen lamps oriented at $45^{\circ}$. The data processed with ENVI $5.2+$ IDL software produced an RGB image ( $R=650 \mathrm{~nm}$; $\mathrm{G}=540 \mathrm{~nm} ; \mathrm{B}=450 \mathrm{~nm}$ ) and grayscale images at wavelengths ranging from 500 to $1000 \mathrm{~nm}$. These pictures were used to indicate specific features such as the original profile of the P letters (a dotted white line in the image at $1000 \mathrm{~nm}$, in fig. 4.5) and their embellishment by the medieval artists (dotted red line on RGB image, in fig. 4.5). The arabesques were added over the original green background and each letter $P$ was embellished differently. 


\section{Stratigraphy of Paint Layers}

\section{The Letters}

A close-up, visual examination, portable microscopy, and micro-technical photography (Dinolite digital microscope $\mathrm{AD} 4113 \mathrm{~T}$ ) were combined to determine the stratigraphy of the mural decoration (fig. 4.6) (Papiashvili 2015). They revealed that the same technique was used to paint the letters $P$ and $M$. The stratigraphy of paint layers is as follows: the white preparation layer (no. 2 in fig. 4.6) was applied on the support and was covered with a yellow underlayer (no. 3 in fig. 4.6). The letters were executed afterwards with a white paint (layer no. 4 in fig. 4.6) which looks heavily cracked.

The elemental analysis of these layers was carried out with non-invasive X-ray fluorescence spectroscopy (XRF) using a Thermo Scientific Niton XL3t 900 spectrometer equipped with a $50 \mathrm{kV} \mathrm{X-ray} \mathrm{tube} \mathrm{with} \mathrm{silver} \mathrm{anode} \mathrm{max.} 40 \mu \mathrm{A}$ and a Si detector with $195 \mathrm{eV}$ resolution (Piqué 2014). The preparation layer (2) is rich in calcium ( $\mathrm{Ca}$ ) while the yellow layer (3) contains iron ( $\mathrm{Fe}$ ) and the white paint layer is rich in lead $(\mathrm{Pb})$. Traces of titanium (Ti) and zinc $(\mathrm{Zn})$ were detected. Micro-destructive examination by Laser Induced Breakdown Spectroscopy (LIBS) using a Nd:YAG laser in the fundamental wavelength (1064 nm) with $45 \mathrm{~mJ}$ energy

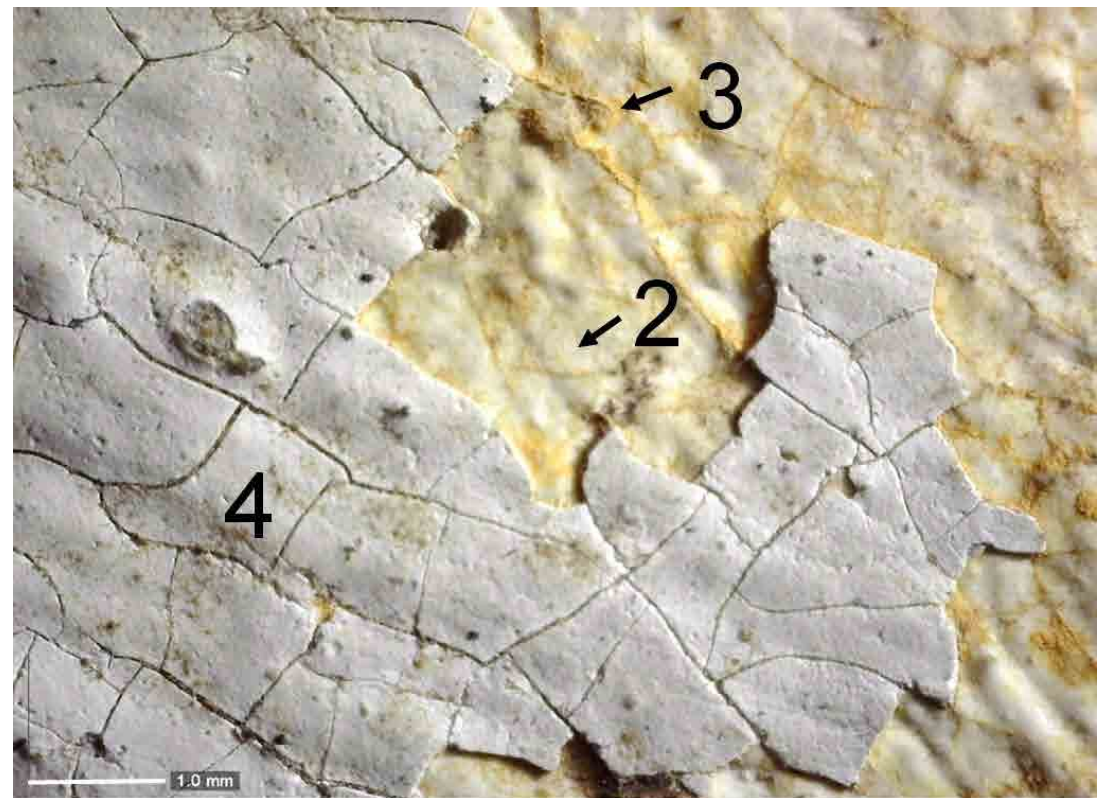

Figure 4.6. Micro observation of a letter $M$ under a Dinolite ${ }^{\circledR}$ microscope. White ground (2), yellow (3), and white (4) paint layers. Photo: Nutsa Papiashvili, 2015. 

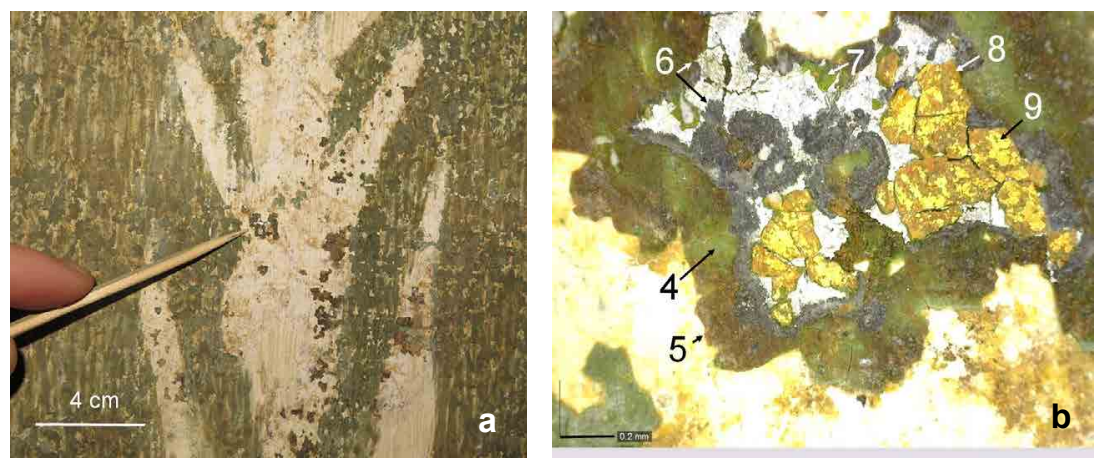

Figure 4.7. Macro (a) to micro (b) observation of a thistle under a Dinolite ${ }^{\circledR}$ microscope. The stratigraphy comprises the underlayers (preparation and yellow layers, the green background (4) and the finishing metallic layers (5 to 9). Photos: Nutsa Papiashvili, 2015.

focusing on $250 \mu \mathrm{m}, 3$ Ocean Optics range between 200 and $950 \mathrm{~nm}$ (from 200 to $340 \mathrm{~nm}$ and from 335 to $445 \mathrm{~nm}, 1800 \mathrm{~mm}^{-1}$ grating, resolution $0.1 \mathrm{~nm}$; from 510 to $940 \mathrm{~nm}, 600 \mathrm{~mm}^{-1}$ grating, resolution $0.31 \mathrm{~nm}$ ) spectrometers and data processing with CALIBSO software confirmed the presence of $\mathrm{Zn}$ and Ti on the white paint layer. Barium (Ba) was also identified, suggesting that possibly lithopone (barium sulphate combined with zinc sulphite) and titanium oxide were used during the recent conservation work. Other elements ( $\mathrm{Pb}, \mathrm{Fe}$, and $\mathrm{Ca}$ ) were also confirmed in the layers below.

\section{The Thistles}

At the time of writing (2016) most of the thistles appear white because only the white Ca-based preparatory layer remains (figs. 4.2a and 4.7a). Green paint layers, as well as the isolated black remains of decoration, are visible in small amounts (fig. 4.7a) where they have not been toned down by white repainting applied during the 1989-95 conservation campaign (Piqué 2013 and Papiashvili 2015).

Visual observation and examination under a portable microscope both revealed a green layer above the yellow underlayer (no. 4 in fig. 4.7b). The green layer corresponds to the overall background of the entire wall. This shows that the thistles were painted over this green background layer. The sophisticated thistle decoration is almost completely lost, but microscopy examination of the remains shows that it was extremely complex and comprised a number of metallic foils (fig. 4.7b). The following order of layers was identified, from bottom up: an orange layer (5) a silvery layer (6) covered with a transparent green layer (7) covered with another orange layer (8) with a gilded layer (9) on top. The systematic analy- 

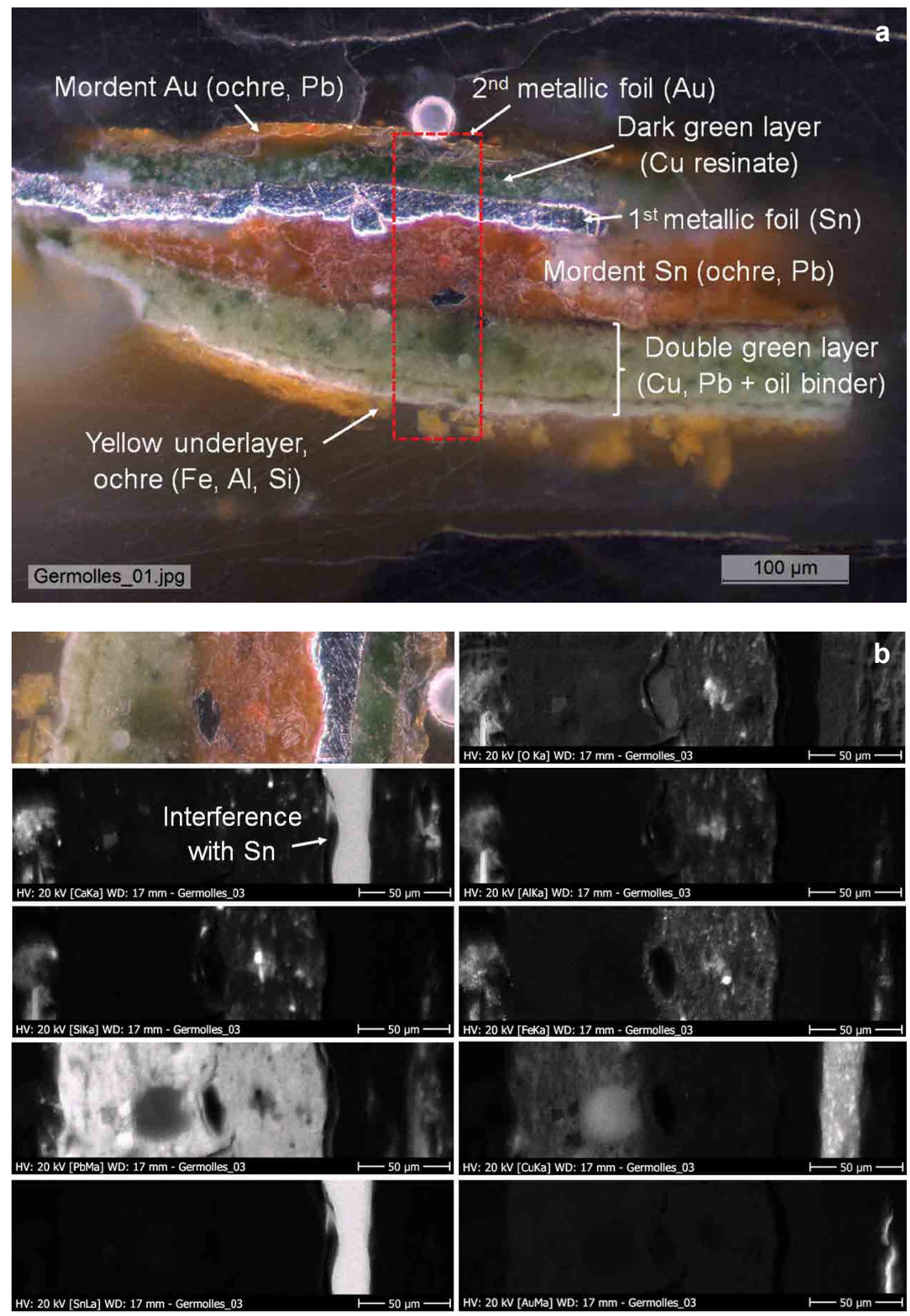

Figure 4.8. Cross-section of a fragment from a thistle, observed in visible light under an optical microscope. The identification of the material was carried out by combining (a) FTIR and SEM-EDS analyses;

(b) elemental mapping of the area in the red, dashed rectangular.

Photos: Francesca Piqué, Dominique Martos-Levif, and Stephan Ramseyer, 2015. 


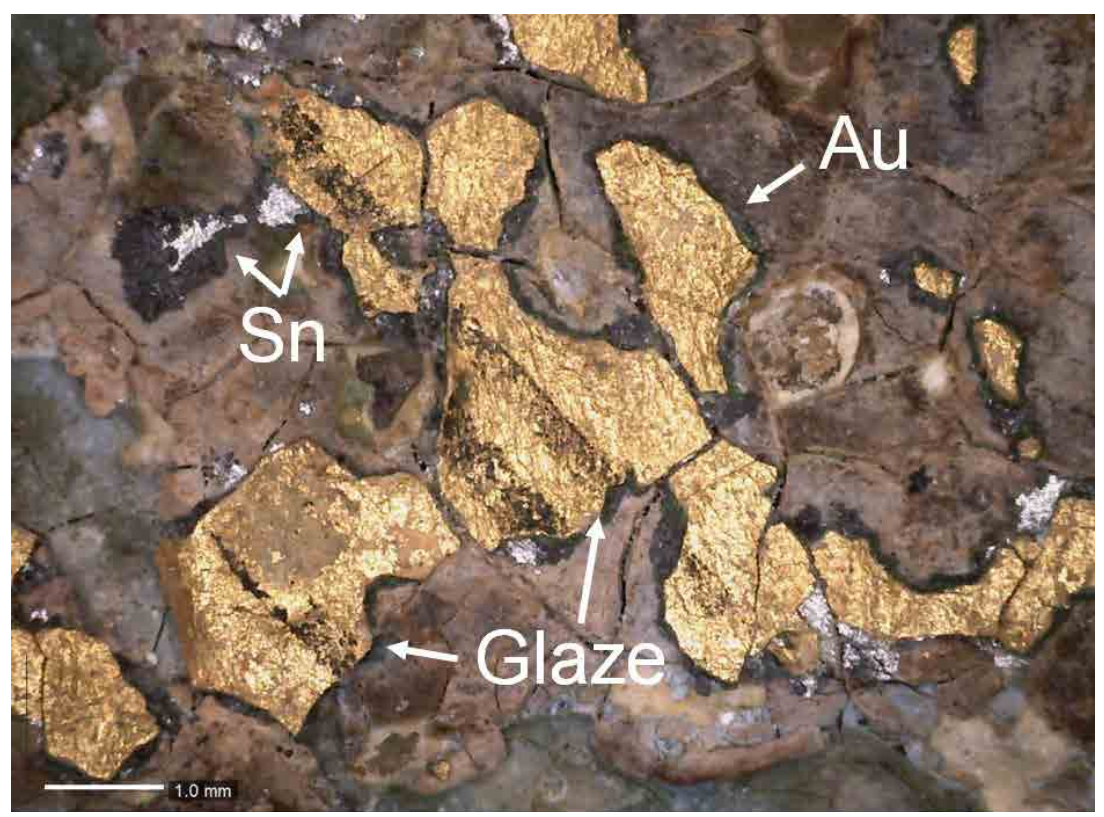

Figure 4.9. Micro-photography of a gold leaf from a thistle in the upper parts of room dn, showing traces of a black glaze or paint layer. Photo: Francesca Piqué, 2014.

sis of these metallic remains by XRF revealed that the silvery layer is tin ( $\mathrm{Sn}$ )-based (Piqué 2014). Tin oxidizes with time and turns black as shown in figure 4.7b. The top layer was made of gold $(\mathrm{Au})$, while copper $(\mathrm{Cu})$ and $\mathrm{Pb}$ were identified on the green background layers. LIBS has confirmed these results.

A small detached metallic fragment of the thistle stratigraphic decoration was mounted in cross-section and examined under an optical microscope. The complete stratigraphy identified visually was confirmed as all layers could be visualized from the powdery yellow underlayer to the upper gold leaf (fig. 4.8a).

Each cross-section layer was further characterized with energy dispersive spectroscopy associated to scanning electron microscopy (EDS-SEM) using JEOL JSM-6400 at a voltage of $20 \mathrm{kV}$, as well as Attenuated Total Reflectance - Fourier Transformed Infrared (ATR-FTIR) spectroscopy using PerkinElmer spectrum 100 equipped with deuterated-triglycine sulphate (DTGS) detectors (4000 to $400 \mathrm{~cm}^{-1}$ ). The yellow underlayer contains both $\mathrm{Fe}$, aluminium ( $\mathrm{Al}$ ), silicon ( $\mathrm{Si}$ ), and $\mathrm{Ca}$ and is probably yellow ochre rich in clays. The green background consists of two layers both containing $\mathrm{Cu}$ and $\mathrm{Pb}$, but in different ratio. The first layer is whiter and contains mainly lead white $\left(\mathrm{PbCO}_{3}\right)_{2} \mathrm{~Pb}(\mathrm{OH})_{2}$ while the second is greener and is richer in a $\mathrm{Cu}$-based green. The binder of these $\mathrm{Cu}$ and $\mathrm{Pb}$ based layers is probably 

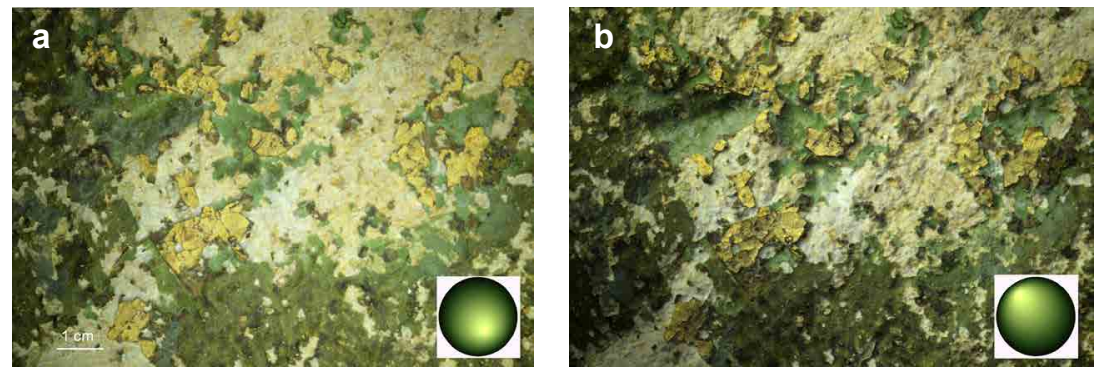

Figure 4.10. H-RTI snapshots under different illumination angles. Gold remains are evident in image (a) but not so much the stratigraphy of layers. The reverse is observed in (b), when the surface is illuminated from the opposite direction. Photos: Gaëtan Le Goïc, Alamin Mansouri, and Château de Germolles, 2015.

oil, as identified through FTIR spectroscopy, and certainly walnut oil, as listed in medieval records (Nash 2010). The orange layers under the metallic leaves have a variable thickness and act as mordants for these layers. Both contain an ochre with $\mathrm{Pb}$ and walnut oil. The green layer on top of the tin is a copper resinate, as identified through FTIR spectroscopy (fig. 4.8b). A black glaze or paint layer was observed on top of some of the gold foils. It was certainly applied to give some relief to the gold background (fig. 4.9) (Mounier 2010).
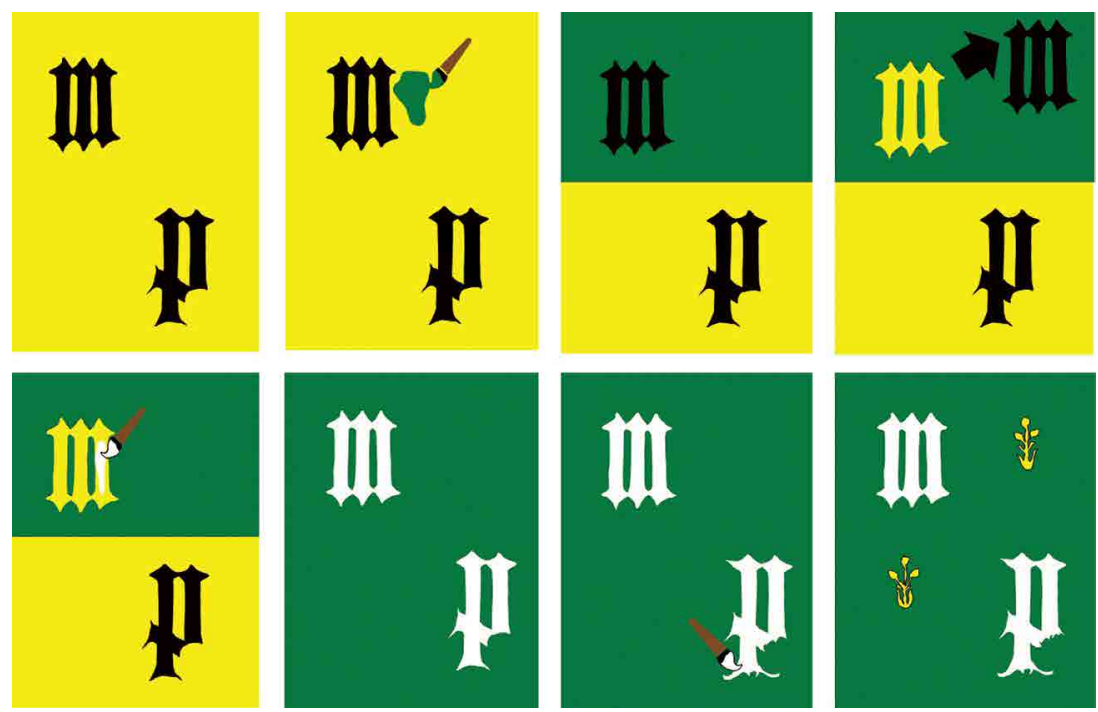

Figure 4.11. Representation of the steps in the historic process of decorating the dressing room of the Countess of Nevers with murals. Photo: Château de Germolles, 2016. 
Highlight-Reflectance Transformation Imaging (H-RTI) using a Nikon D 7100 digital camera equipped with a zoom lens (DX-VR, AF-S 18-140) used with maximum magnification (140 mm), at a working distance of approximately $25 \mathrm{~cm}$, was tested as an alternative to raking light to better visualize the details and stratigraphies of these paintings (Duffy 2013). The surface under observation was illuminated with a torch equipped with an LED of a power of white light (XM L2). Figure 4.10 shows two snapshots of a detail of a thistle, rendered using the Polynomial Texture Mapping (PTM) reconstruction method from an H-RTI recording. The remains of the gold foils are clearly visible in figure $4.10 \mathrm{a}$, while the stratigraphy of layers is more visible in figure $4.10 \mathrm{~b}$.

\section{Painting Techniques Used}

The data collected allow us to hypothesize about the original painting techniques used at Germolles by medieval artists (fig. 4.11).

The lime-based preparation layer was first covered uniformly with a yellow ochre underlayer. The large letters $\mathrm{P}$ and $\mathrm{M}$ were created using stencils, while the green background was painted all around the stencils, in two sub-layers with different $\mathrm{Cu} / \mathrm{Pb}$ ratio, probably bound with walnut oil. The letters were painted afterwards on the yellow ochre using lead white in walnut oil. The profile of the $\mathrm{M}$ letters was not modified further. The arabesques were painted over the green background at the extremities, particularly the lower ones, of the P letters. Thistles were applied in between letters over the green background with mordant. They were made of green tin foils, cut in the shape of the flowers, gilded and further decorated with black glaze or paint layer. The medieval accounts record large quantities, almost 2000 pieces, of green tin foils. This was the largest purchase of this foil by any residence of the Dukes (Nash 2010). Figures 4.8, 4.9, and 4.10 show these metal foils used to make the metallic thistles over the green background. Lead white was used to produce the background as well as $\mathrm{Cu}$-based green, certainly produced locally.

\section{Conservation Condition}

This study was an opportunity to characterize the colour of the paint layers and their possible modification over time. A Minolta CM-700d handheld spectrophotometer was used to compare the reflectance spectra of a recently exposed green background and portions uncovered in the 1970s (Piqué 2014). The results showed that this colour had not changed significantly. Apart from their embellishment, another interesting feature of the P letters is the greyish colour in some areas along their profile (fig. 4.12a). This could be a result of the well-known lead white alteration process (Giovannoni et al. 1990). It is noteworthy that this pos- 

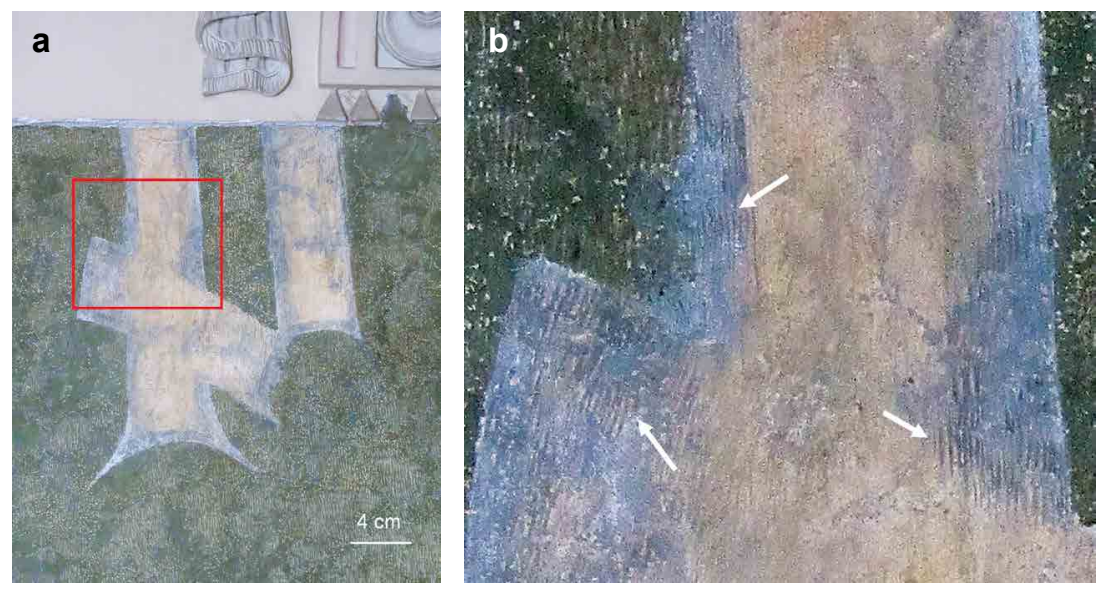

Figure 4.12. (a) Alteration of lead white, creating a shadow effect, observed on the edges of a P letter; (b) details of repainting (indicated by white arrows) the same $P$, applied in the course of the conservation campaign of 1989-95. Photos: Château de Germolles, 2015.

sible alteration seems to be limited to areas where the lead white is covering the $\mathrm{Cu}$-based green background. The repainting carried out at the end of the conservation campaign emphasized these features further (fig. 4.12b).

Due to the ageing of the mural decoration and its alterations in the course of the application of modern plasters, followed by their removal in the 1970s, only traces of metallic decoration have survived. The cross-section of figure 4.8 shows that the layers from the green background to the top gold layer are well attached to each other. This might explain why only the yellow underlayer often remained on the white preparation layer, once the top metallic layers got detached.

A close observation has revealed a complete stratigraphy of layers (where preserved) in all parts of the thistles (flowers, leaves, and stems). This suggests that all the flowers were fully gilded. It is noteworthy that green and not white (not coloured) tin was used. What for, if not to be seen? Green tin was much more expensive than white (Nash 2010).

With the exception of the flaking of some metallic remains, the paint layers are generally stable and adhere well to the surface of the walls. This might be explained by the overall surface consolidation with a solution of Paraloid B72 ${ }^{\circledR}$, carried out during the 1989-95 conservation campaign (Takahashi 1991-94). Visual examination and active IR thermography (IRT) revealed major detachment problems in the upper parts of paintings, below the nineteenth-century cornice. The room was heated artificially to capture images using Thermocamera testo 890 equipped with IR-FPA (focal-plane array) detector. During the dynamic IRT 

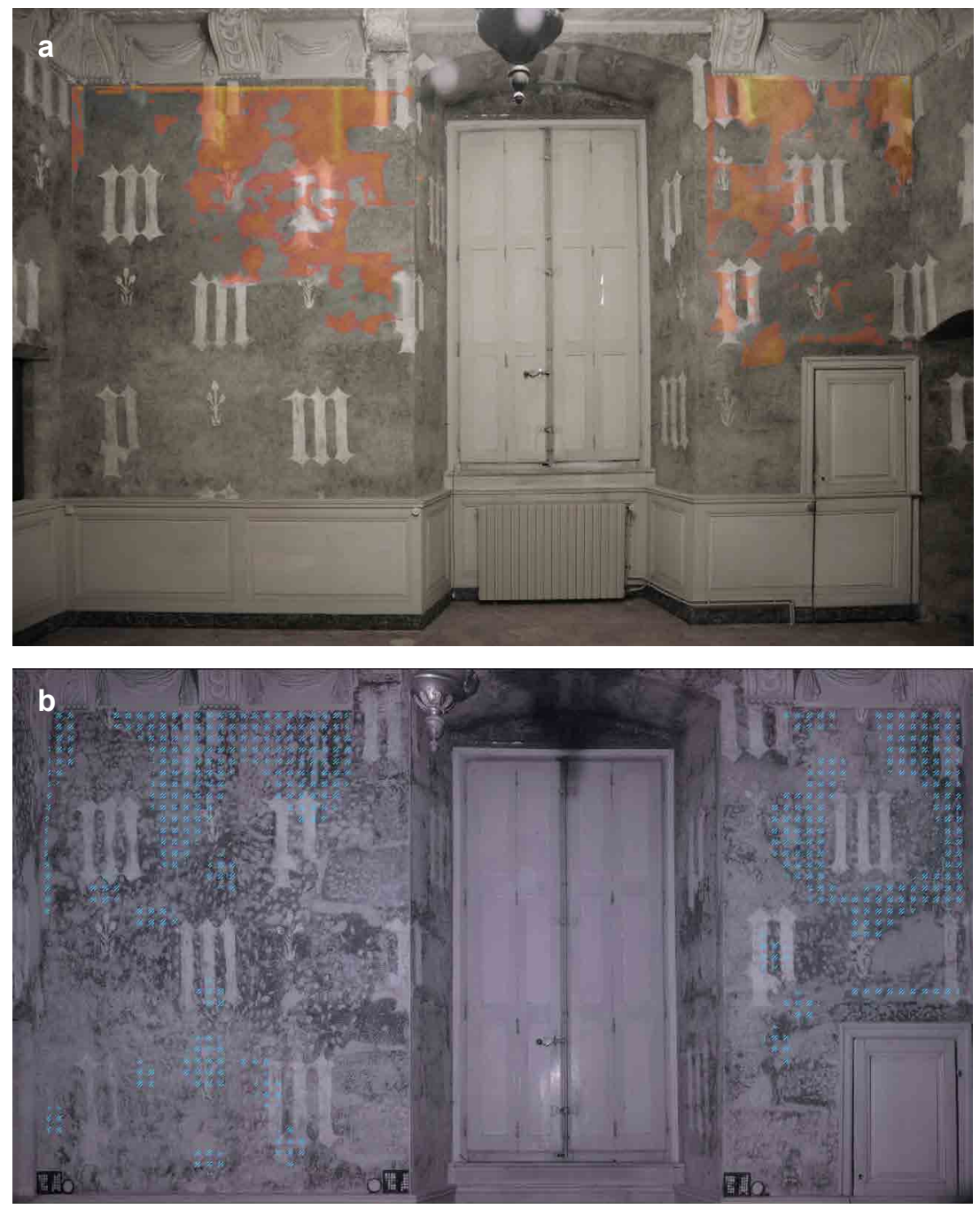

Figure 4.13. (a) Graphical representation through IRT of areas of detachment in the north wall of room dn; (b) representation (overlaid onto an IR image) of similar areas, in blue, as recorded by tactile assessment (knocking method). Photos: (a) Cristina Tedeschi and Marco Cucchi; (b) Nutsa Papiashvili, 2015.

the detached zones heat up faster and could be distinguished with respect to the sound zone. A digital threshold filter was used to retain only pixels which are above a certain temperature and to remove all the others. Figure 4.13a shows the results achieved in room dn, on the north wall. When compared to the graphical representation of the tactile assessment (knocking tests), both results were very 
similar (fig. 4.13b). The same results were achieved on the other walls, indicating that detachment problems occur on all four walls of the room (Tedeschi 2016).

\section{Alignment of Data}

The vast and varied information gathered in the course of this research have contributed to a much better understanding of the materials and techniques used to paint the walls of the medieval residence and of the significance of the surviving decoration. However, the managers of the Château de Germolles are very concerned about the amount of data collected so far and how to manage it to ensure efficient archiving and access. Very large files that can only be visualized using specialist software are a challenge. The files need to be properly named, indexed, archived, and stored for future use.

The alignment of data is a field of research that requires specific expertise in data management (Manuel et al. 2013). Some preliminary tests on data acquired in the course of this case study were carried out (Degrigny 2016). For instance, using a photogrammetry-based point cloud of the room dn south wall, tie points (also called salient or dominant points) were detected over different imaging modalities (different cameras showing different spatial and/or spectral resolutions) such as the P letter in figure 4.14 (Degrigny 2015).

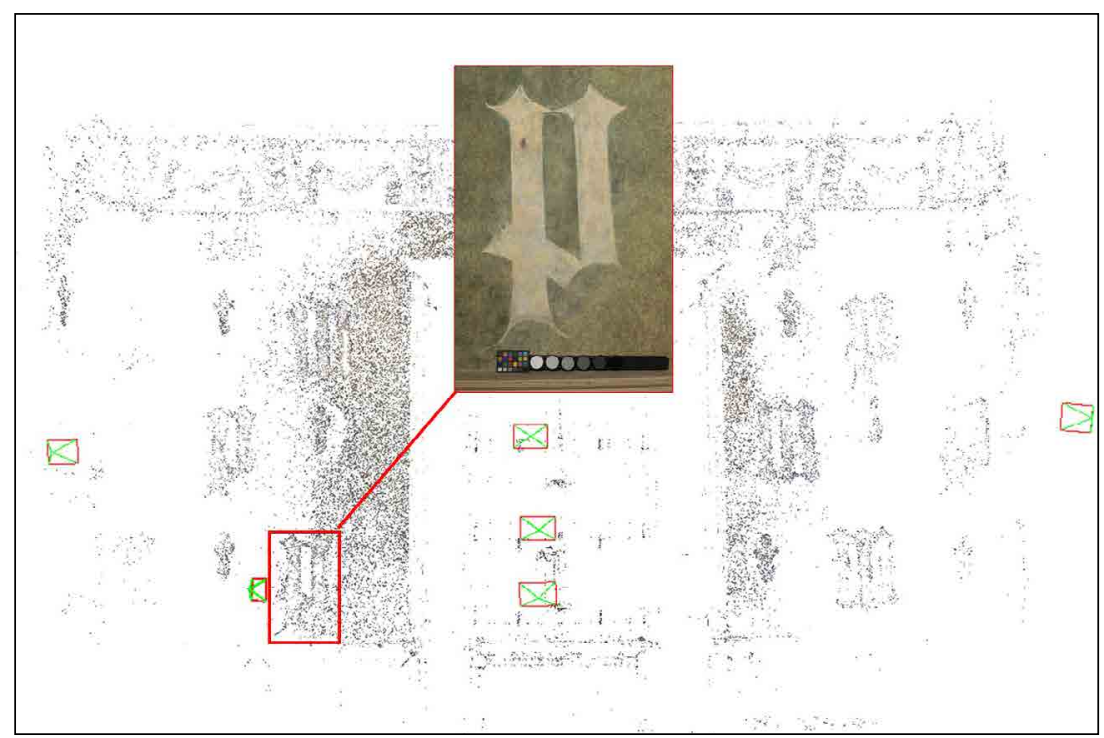

Figure 4.14. Tie points between the point cloud of the south wall of room dn and a technical picture of a $P$ on the same wall.

Photos: Anthony Pamart, 2015 and Francesca Piqué, 2013. 


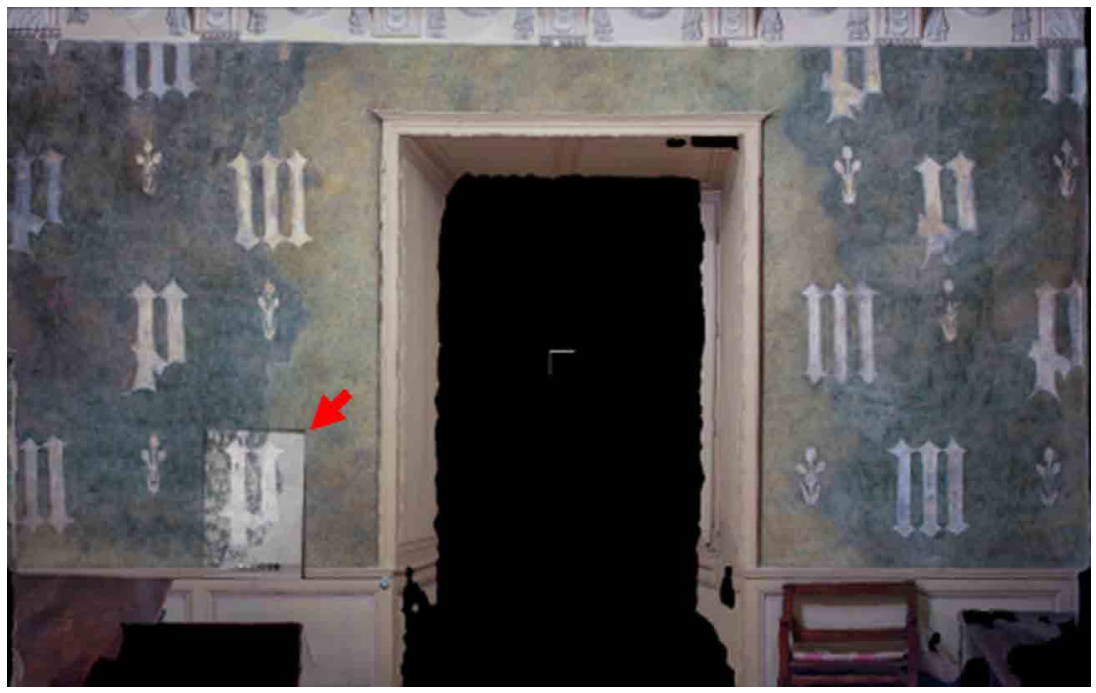

Figure 4.15. Snapshot from the SIVT application tested on Germolles case study data. The rectified and registered IR image of the $P$ (red arrow) is displayed on top of the orthophotography of room dn south wall.

Photos: Stefanie Wefers and Tobias Reich, 2016 and Francesca Piqué, 2013.

Another promising application, Spatial Image analysis and Viewing Tool (SIVT) (Wefers 2016) was tested to provide a combined visualization and analysis of images of the details of the Germolles wall paintings. Different 3D data sets, including orthophotograph of room dn south wall, were registered and integrated into SIVT as basemaps. Images of the details of the wall painting (such as an IR image of the same $P$ as in fig. 4.14) were semi-automatically registered, allowing a combined visualization of the orthophotograph and detailed images (fig. 4.15). This alignment process may potentially enable locating pictures of the wall details, taken during a conservation campaign for documentation, condition monitoring, or conservation intervention.

\section{Augmented Reality Tests}

Dissemination of the information obtained was also a concern. The château being open to the public, the managers were interested in communicating to the visitors the outcomes of this study, in particular the new insights gained into the material history of the decoration. The use of Augmented Reality was considered as a very effective method and non-invasive approach. Tests were carried out on the west wall orthophotograph of figure 4.3. An application was developed for a tablet, using the Unity $3 \mathrm{D}^{\circledR}$ game engine. A virtual scene was constructed from the 

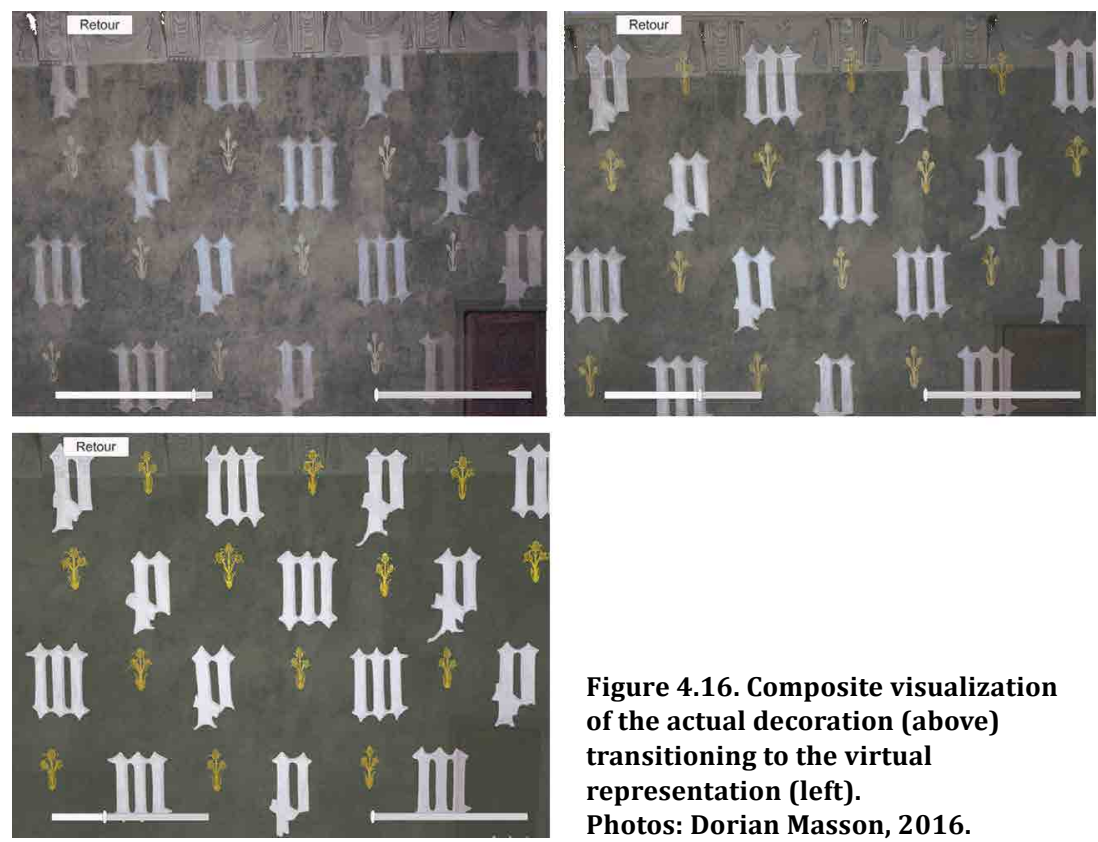

Figure 4.16. Composite visualization of the actual decoration (above) transitioning to the virtual representation (left). Photos: Dorian Masson, 2016.

orthophotograph and existing data collected during the Germolles project: homogeneous green background, white $\mathrm{M} / \mathrm{P}$ letters with arabesques for the latter, and thistles with different profiles but similar to the one found on the floor tiles (fig. $4.2 \mathrm{c}$ ). When facing the wall with the tablet, natural markers (association of letters and thistles) from the orthophotograph of the wall are detected by the Kudan ${ }^{\circledR}$ Software Development Kit used and distances are calculated between the markers and the camera of the tablet. The direction vector of the marker is used to find the similar position on the virtual scene that appears on the tablet. To facilitate an appreciation by visitors of the virtual reconstruction, a joint visualization was created for the tablet that allows progressive movement from the real to the virtual scenes, as shown in figure 4.16 .

\section{Critical Discussion and Evaluation of Research: Future Work}

The onsite examination of the Château de Germolles took place over a period of four years. This gave us the opportunity to test different techniques and eventually select those that were informative. Due to the limited funding and support received, however, the workflow was not the most appropriate. It also depended on the availability of the experts. Logically, the photogrammetric and IR thermographic surveys should have been carried out first, to create basemaps and assess 
the conservation condition of the paintings against their support. We could have continued with other non-invasive investigations, such as macro- and micro-VIS, UV, and IR technical photography, hyperspectral imaging, concurrently with XRF analysis, to assess the level of authenticity of the wall paintings. To better characterize the different stratigraphies of layers, H-RTI and LIBS could have followed on. The invasive examination of samples from cross-sections should have been conducted afterwards. These campaigns could have been accompanied by a final application of colorimetry to assess the colour modification of the paint layers. These results could be used for reference in future surveys.

Some results were more informative than others. The results achieved through the Structured Light Imaging (SLI) could not be exploited due to the lack of lens suitable for the capture of data at the required resolution. Similarly, we did not manage to achieve the level of visualization expected from H-RTI. This drawback can be easily overcome by using a more resolved camera (of higher spatial resolution) which would still make this technique very promising and more accessible to the end-users.

Small hatchings have been observed in the greyish areas along the outlines of the P letters. They are different from the retouching (regular hatchings) applied during the conservation campaign of the 1990s. Their analysis through LIBS revealed the presence of silver. This element could have been used in medieval times. Further investigation would be needed to determine the level of authenticity of other metallic traces. The surface rendering of the metallic thistles remains another important, open question.

The physical instability of the wall paintings has been revealed in close-up examination and quantitatively documented through IR thermography. A thorough survey of both the nineteenth-century cornice and the upper part of the wall paintings will be needed in the future.

\section{Conclusion}

By combining appropriate imaging and analytical techniques we managed to answer some of the questions raised initially, such as the authenticity of Germolles medieval wall paintings and in particular the use of tin foils and gold leafs mentioned in the medieval records. Furthermore the painting techniques used are now better understood: stencilling for the $\mathrm{M}$ and $\mathrm{P}$ letters with arabesques added to the latter and application with mordants of complex metallic decorations for the thistles. Finally the conservation condition of the mural decorations could be assessed: if the paint layers are rather adherent to the preparation layer, areas of detachment from the support have been observed on the upper parts of the walls that will require their thorough monitoring in the future. 
The tools available within the COST Action COSCH, such as short-term scientific missions, and task force meetings have been essential in bringing to the Château de Germolles wall painting conservation professionals and imaging experts who have contributed to the study of the paintings and to the collection of documentation data. The interdisciplinary approach and the integration of the information obtained by the various experts were important to achieve this new level of knowledge. The financial support of DRAC-Burgundy made it possible for us to invite other French experts who joined the interdisciplinary team as constituted.

Among the imaging techniques tested at Germolles, some appeared particularly adapted to end-users. A COSCH training school as a final step in the case study demonstrated the possibilities of photogrammetry, technical photography, and H-RTI applied to the documentation of wall paintings.

The next challenge for the managers of the Château de Germolles is the alignment of all these data. We are just at the beginning of this process, but the new management tools under development are promising. In addition, data management, backup, and migration to new formats are fundamental tasks that will be performed in due course. The managers plan to pursue the Augmented Reality experience by expanding it to the four walls, the ceiling, and floor of Countess of Nevers' dressing room. 